\title{
Sobre o processo de construção do conhecimento: $O$ papel do ensino e da pesquisa
}

\author{
Vera Rudge Werneck
}

\section{Resumo}

O trabalho enfatiza a necessidade da precisão dos termos utilizados na constituição dos saberes para a melhor avaliação da aprendizagem, focalizando, em especial, as noções de construção do conhecimento, e de conhecimento. Reflete, em seguida, sobre o chamado construtivismo e sobre o papel das instituições de ensino quanto aos objetivos do ensino e da pesquisa. Procura demonstrar serem o ensinar e o aprender incumbências da escola enquanto que o fazer ciência é tarefa da comunidade científica, e que, um procedimento não se opõe ao outro. Ambos se complementam embora sejam distintos e com características próprias. $\bigcirc$ docente deve buscar excelência no ensino, assim como o pesquisador, na pesquisa. Considera como ensino não apenas a transmissão do já conhecido, mas o processo que leva à capacidade de observação e de reflexão crítica. $\bigcirc$ bom ensino que deve ocorrer não como um armazenamento de informações, mas como formação de referenciais e desenvolvimento da capacidade de avaliação, o que vai ser fundamental para a produção científica e tecnológica. Mostra ainda serem exigências

da pesquisa científica, metodologia adequada, originalidade, dedicação e investimento financeiro. Chega então à conclusão de que o processo da aprendizagem não se confunde com o da produção científica mas que deve antecedê-lo necessariamente.

Palavras-chave: Construção do conhecimento. Construtivismo. Ensino. Aprendizagem. Pesquisa.

\section{Abstract The process of knowledge construction: the role of teaching and research}

The work emphasizes the need for accuracy in the terms used to describe the acquisition of knowledge, in order to achieve the best assessment of the learning process, with special weight on the notions of knowledge construction and knowledge. Then, the work addresses the notion of constructivism and the role of teaching institutions in the achievement of teaching and research 
goals. It argues that the teaching and learning processes fall under the responsibility of the school, while the scientific community is in charge of scientific production, but one procedure is not in opposition to the other. Instead, one procedure supplements the other, even though they are distinct in nature, each with its own characteristics. A teacher must seek excellence in teaching activities, while a researcher must attempt to achieve excellence in research activities. The author affirms that teaching is not restricted to the transmission of past knowledge, but it also entails a process that gives rise to observation and critical reflection capabilities. Good teaching, which should not be described as the gathering of information, but rather as the formation of references and the development of evaluation capabilities, is of fundamental importance to the scientific and technological production. The work goes on to show that proper methodology, originality, dedication and financial investment are all requirements of scientific research. The conclusion is that the learning process cannot be mistaken for the process of scientific production, but the former must, necessarily, precede the latter. Keywords: Knowledge construction. Constructivism. Teaching. Learning. Research.

\section{Resumen}

Sobre un proceso de construcción del conocimiento: el papel de la enseñaza y de la investigacion científica
El trabajo enfatiza la necesidad de la precisión de los termos utilizados en la constitución de los conocimientos para la mejor avaluación del aprendizaje, enfocando, en especial, las nociones de construcción del conocimiento y el conocimiento. Reflexiona, en seguida, sobre el llamado constructivismo y sobre la función de las instituciones de enseñaza cuanto a los objetivos del enseñaza y de la investigación. Expone, también, que la enseñaza y el aprendizaje son obligaciones de la escuela, mientras el hacer ciencias y tareas de la comunidad científica. Además de destacar que un procedimiento no se opone al otro. Ambos se complementan, aunque sean distintos y con características propias. El docente debe buscar excelencia en la enseñaza, así como el investigador en la investigación científica. Considera como enseñaza no solo la transmisión del ya conocido pero el proceso que encamina a una capacidad de observación y de un análisis crítico. Una buena enseñaza que debe ocurrir no como un almacenamiento de informaciones pero como una formación de referencias y desarrollo de la capacidad de avaluación, que va a ser fundamental para una producción científica y tecnológica. Aun muestra ser exigencias da investigación científica, la metodología adecuada, originalidad, dedicación e inversión financiero. Así se concluí que el proceso de aprendizaje no puede confundirse con la producción científica, pues este debe antecederlo necesariamente.

Palabras clave: Construcción del conocimiento. Constructivismo. Enseñaza. Aprendizaje. Investigacion científica. 


\section{Introdução}

\section{A precisão terminológica}

Um dos maiores obstáculos ao desenvolvimento do conhecimento humano advém da imprecisão dos termos utilizados na constituição dos saberes. Esta dificuldade gera confusões e inadequações de graves conseqüências.

Ensina a Lógica Clássica que os termos podem ser unívocos, equívocos e análogos.

Trabalha-se nas ciências, freqüentemente, com termos análogos sem que se dê conta de que são motivos de desentendimentos e dificuldades de toda ordem.

Termos de significados semelhantes, mas não idênticos devem ser esclarecidos, definidos, delimitados em sua compreensão para que se possa caminhar com maior segurança.

A noção de construção do conhecimento é uma dessas idéias análogas que têm mais de um significado, que pode ser tomada em sentidos diversos devendo ser esclarecida para poder ser melhor utilizada.

Basicamente, é entendida como construção de saberes universalmente aceitos em determinado tempo histórico ou como processo de aprendizagem do sujeito.

\section{A noção de construção}

Considera-se como construção o ato de construir algo, e, como ato ou ação a terceira fase do processo da vontade. Ante um objeto que mobilize o sujeito vão ocorrer três etapas: a deliberação, a decisão e por fim, a execução. A ação é entendida como um processo racional e livre decor- rente portanto da inteligência e da vontade. Embora se possa falar em ato reflexo, ato instintivo e ato espontâneo como movimentos que partem do sujeito independentemente da sua vontade, percebe-se que nesses casos não se tem propriamente um ato, uma ação livre, mas apenas um movimento involuntário indeterminado.

† termo construção aplicado à educação pode ser entendido como já se viu, em dois sentidos:

- como constituição do saber feita pelo estudioso, pelo cientista, pelo filósofo resultante da reflexão e da pesquisa sistemática que leva a novos conhecimentos. Nesse sentido, construíram-se e constroem-se através do tempo, os conteúdos da Física, da Química, da Biologia, da Medicina, [...]. O homem não "descobre" o conhecimento pronto na natureza, mas relaciona os dados dela recebidos constituindo os saberes. A ciência é o resultado desta elaboração mental, da reflexão, do estabelecimento de relações, da observação de causas, de conseqüências, de continuidades, de contigüidades, de oposições, [...]. Pode-se, portanto entender a construção do conhecimento como a constituição dos saberes que resulta da investigação filosófico-científica.

- outra possibilidade de compreensão da idéia de "construção" do conhecimento refere-se apenas ao modo pelo qual cada um apreende a informação e aprende algum conteúdo. Neste caso, o sujeito não propriamente "constrói" o saber, somente apropria-se de um conhecimento já estabelecido. O conteúdo é passado pelo ensino, já pronto e definido embora sempre passí- 
vel de modificações, e cada um vai apreendê-lo de modo semelhante mas não idêntico. Note-se, no entanto, que essa apreensão é feita de modo semelhante por todos, caso contrário não poderia ser entendida pela comunidade científica. Há, como mostra Husserl (1980), uma intersubjetividade entre os que dominam a mesma área do saber que atesta uma identidade na construção do conhecimento.

A chamada "construção do conhecimento" não é então totalmente livre e aleatória levando ao solipsismo e à incomunicabilidade. Ela deve corresponder a uma unidade de pensamento, a uma concordância, a um consenso universal. Não se pode imaginar que possa, cada um, "construir" o seu conhecimento de modo totalmente pessoal e independente sem vínculo com a comunidade científica e com o saber universal.

Nas Meditações Cartesianas afirma ele (HUSSERL, 1980, p. 109):

se realmente toda a mônada é uma unidade absolutamente circunscrita e fechada, todavia a penetração irreal, penetração intencional do outro na minha esfera primordial não é irreal no sentido do sonho ou da fantasia. É o ser que está em comunhão intencional com o outro. É um elo que, por principio, é sui generis, uma comunhão efetiva, que é precisamente a condição transcendental da existência de um mundo, de um mundo de homens e de coisas.

É assim possível uma comunicação intersubjetiva e o que um sujeito cognoscente conhece numa objetividade ló- gica, qualquer outro sujeito pode conhecer do mesmo modo, preenchidas as condições necessárias.

Na própria idéia de ser concreto está contida a idéia de mundo intersubjetivo. Não basta, portanto, descrever a constituição do objeto numa consciência individual. Só por isso não se chega ao objeto como é na vida concreta, mas apenas a uma abstração. Só a redução ao ego não é suficiente. É preciso também descobrir os "outros", o mundo intersubjetivo. Pela intuição fenomenológica da vida do outro chegase à intersubjetividade transcendental completando-se a intuição filosófica da subjetividade.

É de maior interesse para o educador o conhecimento dessa intuição que torna possível a intersubjetividade, e o que faz com que a intersubjetividade não se faça sempre de igual modo, com que grupos mais homogêneos melhor se compreendam, com que possa haver uma comunidade científica, religiosa e ideológica.

Husserl (1980) parte do fato de que, para o ser humano enquanto ego, o mundo é constituído como mundo "objetivo" no sentido de mundo que existe para todo o ser, de mundo que se revela tal como é "na comunidade intersubjetiva do conhecimento".

A partir dessa colocação feita para - conhecimento científico, mas válida para todo conhecimento, chega-se, ao que parece, a uma exigência de conhecimento intersubjetivo idêntico para todos, o que não ocorre. $\bigcirc$ que acontece são níveis de conhecimento intersubje- 
tivo de acordo com os vários níveis de educação, e com os diferentes setores passíveis de educação como o afetivo, o volitivo e o intelectivo.

homem transforma a natureza tanto por sua ação individual quanto social num mundo de cultura que vai para ele aparecer revestido de valor. Cada um compreende a sua cultura tanto no presente como no passado como membro da sociedade que historicamente a formou.

Tomando por base esse fato afirma Husserl (1980, p. 113):

ele deve, a partir disso, criar passo a passo, novos meios de compreensão. Deve, partindo do que é geralmente compreensível, abrir um caminho à compreensão de camadas sempre mais vastas do presente, depois mergulhar nas camadas do passado que por sua vez, facilitam o acesso ao presente.

mundo objetivo como idéia, como correlativo ideal de uma experiência intersubjetiva idealmente concordante, deve ser, por essência, relativo à intersubjetividade que se constitui como ideal de uma comunidade infinita e aberta. Cada comunidade tem, pois, seu modo específico de constituir o mundo objetivo, embora fique garantida a possibilidade de crescimento, de aperfeiçoamento no sentido de busca de plenitude.

\section{O conceito de conhecimento}

$\mathrm{Na}$ busca do saber o sujeito pode adquirir informações empiricamente, aprendendo a fazer sem compreender o nexo causal que dá origem ao fenômeno. Pode ter um conhecimento por experiência como, por exemplo, o modo de dirigir um automóvel sem que tenha a compreensão do processo mecânico que sua ação desencadeia. Pode ainda aceitar, por um comportamento de fé, um ensinamento que lhe é transmitido sem nenhuma consciência de seu conteúdo como é o caso das superstições. Aquele que toma uma cápsula de remédio, acreditando curar a sua doença com tal procedimento, não tem, na maioria das vezes, nenhum conhecimento da relação da substância contida na pílula com o seu mal-estar. Não se pode, nesses casos, falar em conhecimento propriamente dito ou, pelo menos, em conhecimento científico.

Pode-se entender como sabedoria a adequada hierarquização dos valores para a promoção da dignidade humana, o domínio do conhecimento científico e tecnológico de seu tempo, ou a vivência do respeito e da justiça que permitem um melhor desempenho social.

São inúmeras as definições de ciência. Desde a mais sucinta, que a entende como o conhecimento sistematizado das causas do fenômeno, até as mais elaboradas, como a de Baremblitt (1978, p. 16), que diz: "ser uma ciência um sistema de apropriação cognoscitiva do real e de transformação regulada desse real, a partir da definição que a teoria da ciência faz de seu objeto".

Afirma Japiassu (1977, p. 15) que: "É considerado saber, hoje em dia, todo um conjunto de conhecimentos metodicamente adquiridos, mais ou menos sistematicamente organizados, susceptíveis de serem transmitidos por um processo pedagógico de ensino". Empregam-se aí os conceitos de aquisição e de transmissão, mas não o de construção. 
Há, evidentemente, uma pluralidade de discursos científicos e, inúmeras maneiras de se fazer ciência. Cada saber científico tem seu próprio estatuto de cientificidade que deve ser considerado pelo aprendiz.

É ainda Japiassu (1978, p. 98), que volta a afirmar:

A ciência se define por um discurso crítico, pois exerce controle vigilante sobre seus procedimentos utilizando critérios precisos de validação. A demarche científica é, ao mesmo tempo, reflexiva e prospectiva. Os pressupostos de uma ciência são justamente as idéias, os critérios e os princípios que ela emprega na sua efetuação.

Essas afirmações levam à reflexão quando se analisa o conceito de construção do conhecimento. Quais as exigências e os sentidos dessa noção de "construção"?

novo conceito de ciência inicia-se com Kant (1957) com a afirmação de ser a ciência "construída" pelo homem por meio dos juízos sintéticos a priori, contrapondo-se à concepção proveniente do empirismo da apreensão pela experiência, do conhecimento científico captado da própria natureza. Kant vai entender a ciência como constructo humano por meio dos juízos sintéticos a priori.

Com Jean Piaget (2002) iniciam-se as pesquisas de psicologia genética que deram origem ao chamado construtivismo Interacionismo Genético que tinha como objetivo estudar o processo da constituição do conhecimento humano. Não acreditando em inteligência inata, considera que a gênese da razão, da afetividade e da mo- ral, faz-se progressivamente em estágios sucessivos em que é organizado o pensamento lógico, a capacidade de julgamento e a vida moral.

Conhecimento humano inicia-se na primeira infância quando a criança, por imitação repete os gestos, as expressões faciais e as palavras dos adultos com quem convive.

Constitui-se um conhecimento empírico, ligado ao fazer em que pouco se conceitua e muito se apreende pela experiência, pelo senso comum. É uma modalidade de conhecimento altamente influenciada pelo imaginário social, marcada pelo preconceito e pelas interpretações ideológicas.

Com o início do pensamento lógico começam as buscas de relações causais, de simultaneidade, de contigüidade [...]. Os conceitos de substância e de acidentes, de classificação e de ordenamento. Inicia-se a estruturação de um corpo de idéias que vai constituir o conteúdo dos diversos saberes.

À medida que o sujeito atinge o nível de desenvolvimento necessário para a compreensão com a ajuda de elementos externos, o outro, o livro, o professor, a TV, a Internet apropriam-se do novo saber organizando-o a seu modo.

De acordo com as inúmeras concepções filosóficas e epistemológicas varia o entendimento sobre o processo de produção do saber.

Algumas características desse processo são, no entanto, universalmente aceitas nos dias atuais:

- a provisoriedade dos saberes científicos. 
Não mais se aceita o conhecimento como um processo cumulativo. Há, na ciência, uma revisão constante decorrente da possibilidade de novos pontos de vista. $\bigcirc$ mesmo objeto pode ser analisado de diferentes ângulos, o que leva não a um relativismo, mas à constatação da relatividade do conhecimento;

- a interferência do imaginário na produção do conhecimento pela via da cosmovisão e da ideologia.

Admitindo-se como cosmovisão a visão de mundo do sujeito cognoscente pela sua posição histórico-geográfico, cultural e econômica e a ideologia como orientação originária do imaginário que determina os papéis e as funções sociais, percebe-se a interferência desses dois fatores na produção do conhecimento.

- a impossibilidade de neutralidade axiológica.

Não sendo possível a neutralidade e a imparcialidade na constituição dos saberes, há sempre uma interferência dos valores aceitos pelo sujeito na produção do conhecimento.

Embora Piaget (1977, p. 17) considere ser "a inteligência um sistema de operações vivas e atuantes de natureza adaptativa" e afirme que o essencial do pensamento lógico é ser operativo com o fim da constituição de sistemas, não descarta a interferência da afetividade no processo do conhecimento. Reafirma a existência de um paralelo constante entre a vida afetiva e a vida intelectual, considerando-as como dois fatores indissociáveis e complementares em toda a conduta humana.
Tais considerações trazem, senão dificuldades, pelo menos maior exigência de reflexão sobre a noção de construção de conhecimento.

Nos "Seis Estudos de Psicologia" (PIAGET, 1978, p. 15) mostra que "os interesses de uma criança dependem, portanto, a cada momento, do conjunto de noções adquiridas e de suas disposições afetivas já que tendem a completá-los em sentido de melhor equilíbrio". Como ligar a exigência da ação à de equilíbrio? Qual será exatamente o sentido do termo ação? manuseio, ação espontânea ou ato exercido de modo consciente e livre?

Diz ele (PIAGET, 1978, p. 140) ainda: "o equilíbrio não é qualquer coisa de passivo, mas, ao contrário, alguma coisa essencialmente ativa. É preciso, então, uma atividade tanto maior quanto maior for 0 equilíbrio [...]. Portanto, equilíbrio é sinônimo de atividade".

Refere-se ainda ao interesse como essencial a todo ato de assimilação mental. Entende como interesse a expressão do ato de assimilação como incorporação de um objeto à atividade do sujeito, ou seja, o conhecimento ocorre quando o seu objeto traduz-se na atividade do sujeito.

No seu pensar, as estruturas lógicas somente se constituem quando ocorrem ações exercidas sobre os objetos, ou seja, a fonte das operações lógicas é sempre e apenas a própria ação.

Tais afirmações parecem permitir entender o seu conceito de ação como estado mental de atividade, de interesse podendose mesmo encontrar uma relação com a 
noção de intencionalidade de Husserl em que o sujeito busca e assim interfere no objeto do conhecimento.

De qualquer modo, ainda nos "Seis estudos de Psicologia" (PIAGET, 1978, p. 15), mostra que as teorias correntes do desenvolvimento, da gênese, na psicologia da inteligência invocam três fatores, seja um a um, seja simultaneamente: - a maturação, portanto um fator interno estrutural mas hereditário; - a influência do meio físico, da experiência ou do exercício e - a transmissão social.

aprendizado, a construção do conhecimento, exige, portanto, um estado de atividade da parte do sujeito sem que isso signifique ausência de ensino, de transmissão social.

\section{Construtivismo}

que será possível entender-se como construtivismo?

Para J. H. Rossler (2000, p. 7),

o construtivismo constitui-se num ideário epistemológico, psicológico e pedagógico: Afirma ele que "numa primeira aproximação, e também provisoriamente, poderíamos definir o construtivismo como um conjunto de diferentes vertentes teóricas que, apesar de uma aparente heterogeneidade ou diversidades de enfoques no interior de seu pensamento, possuem como núcleo de referência básica a epistemologia genética de Jean Piaget em torno da qual são agregadas certas características que definem a identidade do ideário construtivista como filosófico, psicológico e educacional, compartilhando, assim, um conjunto de pressupostos, conceitos

e princípios teóricos.

Pode-se ainda entender essa teoria como uma crítica a modos inadequados de aprendizagem, modos que não levam à apreensão do conteúdo propriamente dito e, ao mesmo tempo, como uma proposta de investigação sobre as mais adequadas e corretas maneiras de apreendê-lo.

Nesse segundo sentido, o Construtivismo constituiria uma teoria da psicologia da aprendizagem ou mesmo da didática geral.

Como teoria vai, o Construtivismo, propor uma modalidade de aquisição do conhecimento em que o sujeito de modo ativo, compreenda cada fase do processo, perceba os nexos causais existentes entre eles e incorpore como seu aquele conteúdo e não que reconstrua por si mesmo a bagagem científica já constituída.

Talvez se justifique o termo construtivismo como uma condenação ao processo impositivo de transmissão do conhecimento. Levanta a possibilidade de uma transmissão sem imposição e de uma recepção sem a característica da passividade.

Admite então haver uma maneira "certa", "correta", "adequada" de conhecer que não é a da passividade, a da aceitação tácita, a de decorar fórmulas prontas, mas a do sujeito ativo que compreende os conteúdos, que refaz os passos do processo, que busca entender os significados e os sentidos assim como que reconstruir por si próprio o conhecimento.

É importante registrar que o sujeito não vai refazer o caminho da ciência, "re-des- 
cobrir", "re-inventar" os conteúdos dos saberes, mas apreendê-los da maneira correta e adequada que pode ser entendida como uma "re-construção" do conhecimento, de modo que ele venha a constituir parte de si próprio e não como algo justaposto, aceito sem apreensão.

Uso indiscriminado do termo construtivismo pode, por vezes, passar a impressão de que nada pode ser ensinado, transmitido e de que o estudante deve "re-fazer" todo o conhecimento humano por si mesmo.

Podem-se admitir diferentes modalidades de construtivismo. Cesar Coll (2003) registra as seguintes formas:

- o cognitivo que lida com o processo da informação;

- o piagetiano baseado na psicologia genética;

- o de orientação sociocultural baseado na teoria histórica e sociocultural;

- o da psicologia discursiva, da psicologia social que nega a existência de processos psicológicos internos no indivíduo.

socioconstrutivismo foi desenvolvido a partir dos estudos de Vigotsky (2003) e dá grande importância à interação social e à informação lingüistica para a construção do conhecimento. $O$ núcleo do processo passa a ser a funcionalidade da linguagem, o discurso e as condições de produção. Cresce a importância do professor como alguém que interage com os alunos por meio da linguagem.

De qualquer modo, pode-se dizer que a grande contribuição do construtivismo concentra-se na questão do método. Como fazer para que o processo da aprendizagem se faça de modo correto, ou seja, como transmitir o conhecimento de modo que o educando o compreenda, o situe adequadamente e seja capaz de utilizá-lo de modo criativo e independente?

Em primeiro lugar parece necessário terse como objetivo primordial, a organização do pensamento.

Conhece-se algo quando se é capaz de ter desse objeto uma visão de conjunto e de situar as suas partes de uma maneira ordenada.

Algumas noções aparecem como fundamentais nesse processo, como a de espaço e tempo, a de causa e efeito, a de encadeamento lógico, que permite distinguir o princípio, o desenvolvimento e a conclusão.

Torna-se, portanto, uma exigência da análise dessa teoria o estabelecimento de referenciais de avaliação do conhecimento "construído".

A avaliação do conhecimento construído deve considerar a criatividade e a autonomia do sujeito, não se limitando a verificar o êxito de condicionamentos.

objeto da avaliação passa a ser não exatamente o conteúdo do saber, mas o modo segundo o qual ele foi aprendido, ou seja a organização do pensamento do aprendiz.

Basicamente, o construtivismo defende a teoria de que o conhecimento é construído pelo aluno e não transmitido pelo professor. 
Do entendimento do termo nesse sentido, fatalmente vai ocorrer a "construção" do conhecimento. Seja o conteúdo transmitido pelo professor ou descoberto pelo aprendiz vai ele sempre ser organizado e estruturado de modo pessoal e peculiar. Os processos de assimilação e de acomodação são pessoais e intransferíveis, embora não totalmente diferentes em cada um.

Graças à intencionalidade como bem mostrou Husserl (1980), o sujeito vai interferir no objeto do conhecimento construindo-o a seu modo. A rigor, é impossível o conhecimento passivo, puramente receptivo. Todo conhecimento resulta, em última análise, de uma construção do sujeito sobre o seu objeto.

A discussão desloca-se então da epistemologia para a metodologia de ensino. Sobre o melhor método para levar-se o sujeito a apreender o objeto do modo como é universalmente considerado. Sobre como promover uma aprendizagem que não cerceie a criatividade mas a estimule e a desenvolva e, ao mesmo tempo, não leve ao solipsismo e à incomunicabilidade.

Apesar de todas essas informações, é difícil precisar em que consiste o construtivismo, embora seja incontestável o seu sucesso no meio educacional.

Partindo da afirmação não muito clara de que a criança constrói seu próprio conhecimento, essa teoria não explica em que sentido ocorre essa construção.

Algumas contribuições positivas dessa teoria podem todavia ser registradas como:

- uma maior consideração ao nível de desenvolvimento psicológico do aluno.
- a preocupação com a compreensão do conteúdo ensinado.

- a consciência da importância dos aspectos afetivos para a aprendizagem.

- o interesse como motivador da atenção, fator preponderante para a aprendizagem .

No entanto, embora todo conhecimento seja elaborado de modo pessoal e peculiar, embora seja verdade que cada um vivencia e interpreta a realidade a seu modo e do seu ponto de vista, ou há uma intersubjetividade e uma possibilidade de comunicação ou o conhecimento tornase impossível.

Todo ensino visa a transmitir a nova geração o patrimônio cultural acumulado. A questão passa a ser o como, o modo pelo qual esse aprendizado é feito. Embora em todo processo de apreensão esse conteúdo vá ser reinterpretado, esse fenômeno pode dar-se de modo aleatório e passivo ou com consciência e sentido crítico. Nessa segunda modalidade ocorreria uma apropriação do conhecimento semelhante ao processo fisiológico da assimilação que pode talvez corresponder ao que se entende por "construção".

mesmo texto lido, a mesma aula a que se assiste vão ser interpretados diferentemente por cada um mas a comunicabilidade do significado é preservada caso contrário a escrita e a fala tornar-se-iam inúteis.

Afirma João Batista Araújo e Oliveira (2002, p. 166) que:

torna-se óbvio que do ponto de vista lógico, filosófico e científico o termo 'construir conhecimento' não pode referir-se a um relativismo absoluto, seja 
em relação à aprendizagem (tudo que aprendemos seria relativo à nossa forma pessoal de aprender de modo geral, seja referente à verdade idiossincrática de cada texto (só existe o texto que eu leio cujo significado, isto é cuja interpretação e sentido em 'construo').

O construtivismo não pode, portanto, negar o processo do ensino já que ele ocorre desde a mais tenra idade de modo espontâneo ou determinado, mas deve referir-se ao modo correto de ensinar para que ocorra um aprendizado eficaz e, até mesmo, o processo da criação.

Pode-se então entender como construtivismo a corrente teórica que se propõe a conhecer o desenvolvimento da inteligência humana e a ela adequar os métodos de ensino.

Em defesa da possibilidade e da validade do ensino, além das evidências históricas, pode-se recorrer ao conceito de Zona de Desenvolvimento Próxima de Vigostsky (2003) a qual reconhece haver uma diferença entre o que uma criança pode fazer sozinha e o pode realizar se receber ajuda. Essa ajuda é promovida pelo processo do ensino.

A tão falada passividade a que a criança estava condenada pela escola tradicional parece teoricamente impossível já que o processo da aprendizagem exige a ação não como movimento externo mas como intencionalidade, como movimento intelectual de busca e de apreensão. Assim, ou ocorre a atividade intencional por parte do aprendiz ou não ocorre aprendizagem. Nesse sentido, podese admitir que é a pessoa que sempre, com qualquer metodologia de ensino, desde que haja apreensão do conteúdo, constrói o seu próprio conhecimento.

conhecimento resulta da interação do sujeito com o objeto. $\bigcirc$ desenvolvimento cognitivo ocorre pela assimilação do objeto de conhecimento a estruturas próprias e existentes no sujeito e pela acomodação dessas estruturas ao objeto da assimilação.

\section{Os processos de ensino e aprendizagem}

Para o construtivismo, a aprendizagem resultaria de um processo de construção individual do sujeito a partir de suas representações internas. Seria impossível a apreensão da realidade como ela, é, ou seja, o conhecimento objetivo. $\bigcirc$ processo de conhecimento decorreria da interpretação pessoal que, pela experiência, conferiria um significado ao objeto do conhecimento.

Alguns autores consideram a negação da possibilidade de conhecimento objetivo e universal e, portanto, a impossibilidade da apreensão da correspondência entre conhecimento e realidade, como característica fundamental do construtivismo.

Essa posição e a afirmação de que cabe ao sujeito a atribuição de significados e de sentidos leva ao solipsismo e ao relativismo, tornando impossível o conhecimento racional e a comunicação científica.

Pode-se, no entanto, admitir outra interpretação, a que aceita o conhecimento objetivo e universal discutindo apenas a metodologia da aprendizagem e reafirmando a constituição pessoal do conteúdo da aprendizagem pelo aluno. 
Na verdade, parece não haver outra alternativa. Cada um constrói o conhecimento de acordo com o seu modo de ser e de suas capacidades. A afirmação corrente de que $\mathrm{o}$ aluno na pedagogia tradicional receberia passivamente os conteúdos transmitidos pelo professor como já se viu, é bastante discutível a partir da própria epistemologia genética de Piaget (2002). Admitindo-se com ela que todo processo de aprendizagem se dá pela ação, qualquer que seja o método de ensino utilizado, a aprendizagem dependeria da disposição do educando. Estando ele passivo, não haveria aprendizagem.

Há um estado psíquico ativo e um passivo, há um agir que significa fazer, há um agir a esmo e um agir intencional.

Há uma diferença entre o agir espontâneo e o ato livre e consciente direcionado a um fim.

É difícil compreender por que crianças que muito agem como as que têm pouca assistência familiar e escolar, sendo deixadas à própria sorte e tendo, por isso, grande contato com diferentes materiais como água, terra, pedra, madeira [...] e tendo de, pela sua atividade, buscar soluções para os múltiplos obstáculos com que se deparam, não apresentem, em geral, o desenvolvimento mental mais adiantado.

$\bigcirc$ próprio Piaget (2002, p. 51) oferece uma explicação ao afirmar que

não existe experiência pura no sentido do empirismo e que os fatos só são acessíveis se assimilados pelo sujeito o que pressupõe a intervenção de instrumentos lógico-matemáticos de assimilação construindo relações que enquadram ou estruturam esses fatos e os enriquecem na mesma proporção.

Ao mesmo tempo, sabe-se que os instrumentos lógico- matemáticos de assimilação são construídos a partir da ação. Fecha-se então o círculo, deixando interrogações.

Mostra ainda esse autor (PIAGET, 2002, p. 51), "que não há processos em sentido único, visto que se uma forma operatória é sempre necessária para estruturar os conteúdos, estes podem freqüentemente favorecer a construção de novas estruturas adequadas".

Percebe-se então a importância da aprendizagem de conteúdos para a constituição de novas estruturas responsáveis por novas formas operatórias. De qualquer modo é, nesse contexto, difícil a compreensão de como ocorre a passagem das formas iniciais do conhecimento para as formas superiores. Em que medida resultam de uma mudança de paradigma fundamentada nas capacidades de abstração e de reflexão.

A necessidade de aprendizagem leva à necessidade de ensino e de ensino adequado.

- No pensar de Alessandra Arce (2000, p. 56), é fundamental para o professor um aprofundamento na epistemologia genética e no desenvolvimento infantil a partir da visão construtivista, levando em consideração os seguintes itens:

- o conhecimento da realidade não constitui cópia objetiva dessa realidade, dependendo sempre de interpretações pessoais.

- as construções ocorrem sempre dentro dos padrões de acomodação e de assimilação. 
- Aprender é um processo de construção e não de acumulação.

- $O$ significado da aprendizagem é reflexo da resolução de conflitos que ela provoca.

Ao que parece, se, conforme mostra a epistemologia genética, o desenvolvimento infantil segue sempre os mesmos passos, seria impossível que o conhecimento se constituísse em cópia da realidade independente da metodologia de ensino utilizada.

Com qualquer metodologia de ensino as construções ocorreriam dentro dos processos de acomodação e de assimilação, ou não existiriam.

Seria impossível, teoricamente, o processo de acumulação.

Para o construtivismo o sujeito constrói o próprio conhecimento a partir de suas representações internas. A aprendizagem resulta dessa construção.

Pode-se, no entanto, propiciar essa aprendizagem proporcionando experiências, enriquecendo o dia a dia do sujeito com materiais didáticos adequados e situações de vida que induzam e facilitem essas experiências.

$\bigcirc$ conhecimento resultaria de um processo de construção pessoal, de atribuição de sentidos e significados pelo sujeito que, de certo modo, restringiria a possibilidade do conhecimento objetivo e universal.

Fica sempre a pergunta sobre se o conceito de construção em Piaget implica em ato livre ou se apenas significa processo de formação de conhecimento que ocorre independentemente da vontade do sujeito.

Sabe-se que o sujeito interfere no conhecimento com a sua intencionalidade, o que faz com que o mesmo conteúdo seja apreendido diferentemente por cada um, resguardando-se, no entanto, a identidade do objeto.

Mesmo admitindo-se como fundamental o papel da ação do sujeito na aquisição do conhecimento, pode-se falar em aprendizagem como um processo que não supõe a sua passividade mas a interferência do outro.

Novamente na sua Epistemologia Genética (PIAGET, 2002, p. 91), encontra-se a afirmação de que "a experiência não basta para assegurar a formação de operações novas" e de que "é fundamental a atividade operatória do sujeito para a construção dos instrumentos adequados de leitura e para a construção de estruturas explicativas". Chega-se então a que, para não aterse apenas ao nível da experiência mas para atingir-se o nível da atividade operatória, é preciso um direcionamento. Entra aí o papel do educador como propiciador da aprendizagem, como aquele que vai adaptar o ensino aos ensinamentos da psicologia do desenvolvimento.

Esta, pode-se dizer é a grande contribuição de Piaget que deve ainda ser meIhor aproveitada especialmente pelos autores didáticos: a adequação entre o desenvolvimento psíquico do estudante e as técnicas de ensino e do material didático.

Afirma ainda ele (PIAGET, 2002, p. 4): é evidente que toda pesquisa em epis- 
temologia genética, quer do desenvolvimento de um certo setor do conhecimento na criança (número, velocidade, causalidade física [...]), quer de uma transformação num dos ramos correspondentes do pensamento científico, pressupõe a colaboração de especialistas da epistemologia da ciência considerada.

Relacionando-se a idéia de construção de conhecimento à didática, aos métodos de ensino, chega-se à importância da ligação dos estudos de psicologia nas suas diversas áreas com a constituição dos currículos.

Sabe-se que o processo de aprendizagem da ciência vai exigir a desconstrução do saber empírico. Sendo a ciência um novo olhar, um outro modo de ver o real, vai exigir uma metodologia própria que deve ser introduzida pelas instituições de ensino.

conhecimento acadêmico é um processo contínuo de correção de rumos que embora histórico ultrapassa as relações sociais, as concepções de mundo e as ideologias.

Ao que parece, Piaget fala em desenvolvimento como um processo que se faz espontaneamente e não de construção como prática consciente e deliberada. A aquisição do conhecimento dar-se-ia espontaneamente provocada pela experiência e pela influência social.

Como os estudos da psicologia da inteligência mostram não serem as estruturas lógicas inatas, mas "construídas" for- madas pouco a pouco, vê-se que a idéia de processo de desenvolvimento como "construção" não é entendida como ato livre e consciente.

Também a questão da avaliação se reporta à noção de construção. As práticas de avaliação são bons indicadores da expectativa da escola quanto à aprendizagem dos conteúdos propostos.

Há a necessidade inicial do estabelecimento de critérios pedagogicamente justificáveis para a seleção dos conteúdos programados para cada etapa do desenvolvimento.

O ensino de certas ciências como a matemática, por exemplo, exige níveis de abstração muitas vezes incompatíveis com o estágio de desenvolvimento da criança.

Para que se perceba o conhecimento construído é necessária a avaliação do progresso do educando, comparando-o com ele próprio em avaliações anteriores.

O nível do conhecimento manifestase ainda na utilização prática que dele se faz. Pode-se observar em que medida, no seu dia-a-dia, o sujeito emprega o conhecimento aprendido.

Tem conhecimento quem é capaz de distinguir o essencial do acidental, aquele capaz de ordenar e hierarquizar os dados, de situar no tempo e no espaço de definir causas e conseqüências.

Considerando-se que a vida afeti$v a$, embora distinta, é inseparável da cognitiva, também esse aspecto deve ser avaliado. 
A construção do conhecimento como processo de aprendizagem do sujeito depende de um lado, do desenvolvimento de suas estruturas cognitivas e do outro, do modo pelo qual os conteúdos do conhecimento the são apresentados.

O conhecimento em geral resulta da construção do sentido a partir de um texto lido ou de uma exposição de um professor. Percebe-se, no entanto, que não é aceito qualquer sentido, mas somente aquele adequado, ou seja, não há propriamente uma construção livre, pessoal e independente, mas um processo de aprendizagem, de incorporação de um conteúdo que deve ser feito de determinado modo para que seja garantida a comunicação entre os que têm o mesmo conhecimento.

Para a melhor compreensão do processo da consciência, pode-se fazer um paralelo entre a consciência ativa de Piaget e a teoria da intencionalidade de Husserl (apud BACHELARD, 1957).

A teoria do conhecimento que estuda as questões das relações entre a consciência e o ser perceberá a correlação entre eles. O ser aparecerá como alguma coisa conhecida, segundo a maneira da consciência. Não se pode deixar de lado - fato de que a consciência individual tem um modo próprio de conhecer e usar que não pode ser ignorado pela teoria da educação.

Do conhecimento adequado de si mesmo, do mundo e do outro vai resultar um tipo de intencionalidade, embora esse mesmo conhecimento seja decorrente dela.
A intencionalidade vai, pois, caracterizar toda a vida psíquica e dar o sentido do próprio "eu", do outro e do mundo. A análise intencional vai esclarecer o modo pelo qual é constituído o sentido de ser do objeto, já que a intencionalidade é não somente um "tender para", mas ainda uma doação de sentido.

Husserl vê a consciência como uma intenção dirigida para o objeto que, portanto, nela não está contido como fenômeno. A intencionalidade caracteriza a consciência.

A intencionalidade é o modo de a consciência visar ao seu objeto, sendo diferente em cada um, embora com uma base comum.

A estrutura da consciência e da intencionalidade mostram seu caráter pessoal. A vida psíquica não se apresenta como uma corrente anônima no tempo. O vivido pertence sempre ao sujeito. Os atos procedem do "eu" que neles vive e conforme o modo como os vive, vai-se distinguir a receptividade da espontaneidade da consciência, da intencionalidade.

A intencionalidade vai dar o sentido do conhecimento e a significação do conhecido.

Husserl (apud BACHELARD, 1957, p. 315) insiste no fato de que a consciência se relaciona sempre a alguma coisa e na existência de variedades especificas da relação intencional: os modos representativo, judicativo, volitivo, emotivo e estético, aos quais o objeto visa de maneiras diversas. Existiria, no entanto, uma maneira adequada de assim proceder que garantiria a autenticidade e a validade do conhecimento. 
A intencionalidade de como direcionar dando um sentido, não diz respeito unicamente à vida teórica, mas ainda a todas as formas de vida que se caracterizam por uma relação com o objeto.

Essa observação é especialmente importante para a proposta da educação já que ela toma o sujeito na sua globalidade e não apenas no seu aspecto cognoscitivo. Há, assim, um direcionamento dele ao tender para os valores, ao desejar algo, ao agir, ao amar, ao alegrar-se [...] que o caracterizam como um ser ativo.

Embora a intencionalidade faça que os objetos sejam percebidos de modos diversos por cada um, ao reconhecer a existência do objeto exterior afasta-se do relativismo e aponta para uma relatividade, não propriamente quanto ao conhecimento, mas quanto ao seu sentido.

Continuando o relacionamento do pensamento de Husserl com o de Piaget, vê-se que o fenômeno da atenção, no seu pensar, não constitui um ato diferente dos outros, mas um modo de ser possível a todos os atos. Ela não muda a intencionalidade, não a cria, mas é, de certa maneira, uma modificação subjetiva porque no interior de cada subjetividade se traduz a maneira segundo a qual o "eu" se relaciona com o seu objeto. No ato da atenção, o "eu" está ativo. Nos atos onde não há atenção no âmbito potencial, o "eu" não se ocupa diretamente com as coisas dadas. Não se dirige ativamente ao objeto. Pode-se concluir ser esta a condição para a aprendizagem.

A questão da intencionalidade pode ainda ser relacionada com a tendência própria do ser humano para a busca e a apreensão dos valores. As carências das várias áreas do sujeito levam-no a tender não propriamente para os entes mas para valores que portam.

O conteúdo deve ser apresentado como valor ou seja como algo que, de algum modo, vá preencher as necessidades do sujeito. Para tanto, pede-se o concurso da Psicologia do Desenvolvimento onde é inestimável a contribuição de Piaget, da Psicologia da aprendizagem e da Didática.

\section{O papel das instituições de ensino}

$\bigcirc$ ideal do ensino e da aprendizagem corretos não é novo. Data da mais remota antigüidade. Já se encontra na indução socrática com a proposta de levar o educando a buscar a verdade em si mesmo.

É bastante freqüente a exigência do estado de atividade por parte do aprendiz. Atividade que não se restringe à atividade física, ao fazer ou ao agir, mas no sentido de atividade mental que leva o educando a sair de si mesmo em busca do saber. $\bigcirc$ estar passivo entendido como um estado de ausência, apatia, distanciamento, desinteresse ou desatenção apresenta-se como empecilho à aprendizagem.

Cabe então ao educador aprofundar o seu objeto de conhecimento, o ensino e a aprendizagem para melhor chegar ao seu objetivo.

Não se confundem o processo de fazer ciência com o de aprendê-la. Ensinar e aprender ciência é função da escola. Fazer 
ciência é tarefa da comunidade científica. Um procedimento não se opõe ao outro. Ambos se complementam, embora sejam distintos e com características próprias.

aprendizado da ciência vai exigir o conhecimento da metodologia científica, do processo histórico que a justifica, dos diferentes estatutos de cientificidade. Mais do que propriamente fazer ciência, é tarefa das instituições de ensino oferecer este conhecimento. Seu objetivo é preparar o futuro pesquisador, o futuro cientista e o objeto de seu labor é o aprendizado do estudante.

Não significa essa afirmação a defesa de um modelo de transmissão de conhecimento que não leve o aprendiz a buscar, de modo ativo, uma mudança conceitual, que se vão entregar conteúdos prontos para serem aceitos, fixados, internalizados sem reflexão críti$\mathrm{ca}$, mas que se procurem processos didáticos que facilitem e aprimorem o aprendizado.

A noção de produção de conhecimento na escola é dúbia e discutível. Justificase, se entendida como aprendizado individual. Caso contrário, só ocorreria esporadicamente, já que pressupõe por parte do autor reflexão crítica, maturidade e conhecimento sistematizado.

discurso pedagógico resulta de uma recontextualização do discurso científico para torná-lo acessível ao conhecimento escolar. É um discurso que se adapta ao nível de desenvolvimento do aluno.

A escola de ensino Fundamental e Médio vai apropriar-se do conhecimento científico atualizado para disponibilizá-lo ao aluno. Desse modo propicia o seu contato com os conhecimentos relativos à nature- za, à vida social e com toda a produção científica, ao mesmo tempo em que o inicia na metodologia da ciência, despertando a capacidade crítica e preparando o futuro pesquisador.

Talvez seja essa uma das principais metas da escola: a instrumentalização para a produção e o consumo da ciência.

Na verdade, o conteúdo transmitido pela escola não se constitue apenas da seleção e organização do conhecimento científico de modo a torná-lo adequado e acessível ao nível de desenvolvimento psicológico dos alunos mas apresenta-se como uma modalidade de saber com características próprias.

A concepção crítica do conhecimento entende o saber não como constituído por dados prontos e definitivos mas como um conjunto provisório em constante processo de revisão e de reconstrução.

Torna-se então fundamental para a escola a constante atualização do conteúdo das suas disciplinas e a avaliação dos seus processos de ensino para proteger-se da grande interferência do imaginário social dada a impossibilidade da sua neutralidade.

Vai ser necessário ao professor a constante atualização, o interesse pela sua disciplina, a capacidade de observação e de interpretação do real para uma boa atuação. Importa mais o espírito de pesquisa, o despertar do aluno para a observação e a reflexão do que a própria pesquisa de campo que exige tempo e dedicação para a sua conclusão. $\bigcirc$ docente deve buscar excelência na docência, assim como o pesquisador, na pesquisa. 
Ensino não é apenas a transmissão do já conhecido, mas o processo que leva à capacidade de observação e de reflexão crítica.

Percebe-se, nos dias de hoje, um preconceito contra o ensino como se fosse ele uma atividade menor, como se fosse um processo condenável por si mesmo. Podemse questionar os seus métodos, buscar o seu aprimoramento, mas, sendo o homem um ser social, a transmissão da bagagem de conteúdos e da reflexão crítica de uma geração para a seguinte é inevitável e fundamental.

Cabe à escola a socialização do conhecimento, a instigação à curiosidade, a instauração do hábito do rigor metodológico, mas não propriamente a produção da ciência.

Afirmações que atribuem à escola a produção do saber sem maiores explicações levam a mal-entendidos. A educação pode promover o saber no sujeito ao qual se direciona mas não, necessariamente, produzir novos conhecimentos de validade universal.

objetivo primordial das instituições de ensino, seja em que nível for, não é a produção de saberes no sentido de resultados de pesquisa científica mas construção individual de conhecimento.

Quando se afirma que cabe às universidades gerar saber, não se esclarece o sentido da afirmação. Ela significa produzir conhecimento que possam ser universalmente aceito ou gerar conhecimentos no estudante? São compreensões diferentes que não se excluem mas não se confundem.
Pode-se, sem dúvida, considerar como uma das funções da universidade a produção do conhecimento, embora se perceba que, na maioria das vezes os avanços da ciência ocorreram e ocorrem fora da universidade. Foram promovidos pelas Academias de Ciência ou mesmo pelo interesse das grandes empresas. A outra função, talvez a principal, por expressar seu objetivo primeiro, seria a socialização do conhecimento por meio do ensino e a sua aplicação prática pela extensão.

$\bigcirc$ bom professor é o que se preocupa com o ensino e com a aprendizagem. Para isso, deve aprimorar-se, buscar novas técnicas, pesquisar sobre o tema. Outra modalidade de atividade é a pesquisa propriamente dita. Um excelente professor pode não ser um bom pesquisador e vice-versa.

A universidade moderna, ao ensinar a pensar, a criticar, a analisar, a sintetizar, está cumprindo a sua missão de promover o aprimoramento humano, a transformação social e a de preparar o sujeito para a produção do conhecimento. Divulgar saberes existentes com a reflexão crítica é o melhor modo de propiciar a produção do conhecimento.

Não se podem saltar etapas. A tentativa de criação de conhecimentos sem o devido embasamento teórico leva a resultados de qualidade inferior que se acumulam esquecidos nas bibliotecas.

conhecimento científico começou como uma produção individual. Grandes gênios observaram a natureza, estabeleceram relações e constituíram saberes que foram aceitos como válidos ao longo do tempo. 
Com o aumento das informações e com o cruzamento dos dados de inumeráveis pesquisas de indivíduos e de grupos, a complexidade chegou a tal ponto que a produção do conhecimento humano passou a ser feita por empresas que detinham grande poder econômico para atender às demandas cada vez maiores das pesquisas sempre mais complexas.

Por muito tempo coube às universidades a seleção, a organização e a transmissão dos saberes. Coube a ela o estabelecimento do mínimo a ser exigido para que fosse conferido o grau ao aluno, para que ele fosse considerado detentor de um saber que lhe permitiria certas prerrogativas como o exercício profissional.

Hoje alguns profissionais como o advogado, devem submeter-se ao exame de corporações profissionais como a Ordem dos Advogados para poderem exercer o seu ofício.

Somente no século XX entendeu-se caber à universidade não apenas o ensino, mas também a pesquisa como produção de conhecimento e, até mesmo, a extensão como serviço à sociedade.

conceito de pesquisa também merece um aprofundamento. $\bigcirc$ termo é tomado numa tão vasta amplidão que engloba, desde recortes de jornais e revistas nas classes iniciais, até trabalhos teóricos de grande envergadura.

Pesquisas científicas exigem metodologia adequada, originalidade, grande dedicação e investimento financeiro. A multiplicidade de pequenas pesquisas para cum- primento de exigências acadêmicas apenas confirmam o que já se sabe ou trazem contribuições de pouca importância.

Ensino na Universidade, a partir do século XVIII, procura incorporar ao conteúdo clássico os novos conhecimentos produzidos pela ciência experimental e, ao mesmo tempo, capacitar os alunos para as novas profissões. Procura assim novos métodos de ensino e técnicas de aprendizagem mais modernas.

É sabido que, na época moderna, a pesquisa científica desenvolveu-se especialmente fora das instituições universitárias. Só no início do século XIX, na Universidade de Berlim, começa propriamente a integração entre ensino e pesquisa científica. $\bigcirc$ professor, além de conhecer o seu campo específico do saber, deveria pesquisar novas soluções para os problemas de sua área de conhecimento.

Mostra Newton Sucupira (1978, p. 14) que "a figura do sábio solitário em seu laboratório é hoje inconcebível. A ciência é obra coletiva que depende de técnicas especiais, laboratórios custosos, financiamentos maciços e vasta equipe de cientistas".

Essa afirmação quase inviabiliza a figura do professor pesquisador. Ou bem que ensina ou bem que pesquisa. Caso pesquise, o faz de modo muito limitado ou então atém-se à pesquisa teórica não indo a campo.

Considerando-se os objetivos primordiais da universidade do desenvolvimento do sujeito e da divulgação do conhecimento científico, a pesquisa se justificaria como um meio do ensino da ciência, como técnica didática. 
A primazia da dedicação à pesquisa no sentido de construção de conhecimento para a humanidade dificulta o exercício da função precípua na Universidade que seria a reflexão crítica sobre a vida social, científica e política. A universidade é eminentemente crítica e, por isso, precisa ser livre e independente de ideologias e do poder econômico ou do Estado. Deve transmitir o conhecimento acumulado cuidando para que seja adequadamente construído no sujeito e assim propiciar o desenvolvimento da pesquisa.

Novamente é Newton Sucupira (1978, p. 10) quem diz:

Se muitos se queixam de que os deveres do ensino absorvem os professores impedindo-os de se dedicarem mais livremente à pesquisa cientifica, outros acentuam que a predominância da pesquisa em detrimento do ensino termina por prejudicar a formação do estudante ao nível da graduação como estaria acontecendo em certas universidades americanas.

Continua ele (SUCUPIRA, 1978, p. 16): Hoje, nos Estados Unidos, a pesquisa de desenvolvimento se faz preponderantemente na indústria ou em organismos governamentais, enquanto a pesquisa básica se processa preferentemente na universidade. Esta é que prepara os pesquisadores para a industria e os grandes cientistas puros se encontram na universidade.

Embora já um tanto distante no tempo, é de grande importância a contribuição do Professor Sucupira, distinguindo duas modalidades de pesquisa: a pesquisa básica e a de desenvolvimento. Talvez se possa considerar como pesquisa básica a que busca reformar, corrigir e consolidar os fundamentos da ciência por meio da discussão, da reflexão crítica e de experiências fundamentais e, como pesquisa de desenvolvimento a que serve à industria e à tecnologia e, assim, indiretamente à organização da produção e da sociedade. Atualmente essa pesquisa de desenvolvimento é, em grande parte, promovida pelas chamadas Universidades Corporativas que têm objetivos práticos definidos e condições econômicas para sustentá-las.

$O$ processo mestre $x$ oficial da Idade Média era uma modalidade de ensino extremamente eficaz. Hoje, contornam-se as dificuldades econômicas com as chamadas Universidades Corporativas. Volta-se de certo modo a esse processo. São as empresas que com seu poder econômico, montam grandes laboratórios e mantêm seus pesquisadores para que possam ter dedicação exclusiva.

Quando a Universidade abre mão da reflexão crítica para ater-se apenas aos aspectos quantitativos do real, deixa de cumprir seu objetivo principal: o embasamento do conhecimento do aluno pela instauração da reflexão filosófica, da capacidade de avaliação e de crítica para tentar uma performance para a qual não tem as condições econômicas exigidas.

Não significa ser menos ambicioso buscar a excelência no ensino como fundamentação para futuras pesquisas. Note-se, novamente que a pesquisa pode também ser utilizada como metodologia de ensino para uma melhor aprendizagem. 
É possível admitir-se que, no momento, faz-se necessária uma pesquisa sobre os melhores métodos e técnicas para um ensino eficiente.

A epistemologia genética vai ser de grande valia para o desenvolvimento do conhecimento pedagógico. Dela vai depender a ação pedagógica que pode ajudar ou dificultar o processo de construção do conhecimento de cada estudante.

A pesquisa na universidade assim como o ensino, são considerados como parte da educação. Quando desvinculados da promoção humana, do seu aprimoramento global, dos valores da família, da idéia de nação apenas respondendo aos interesses do estado ou do mercado, desvirtuam-se constituindo empecilhos a esse processo.

Dificilmente vai a Universidade, produzir novos saberes se não atentar para 0 aprimoramento do ensino que, como já foi visto, não se reduz à simples transmissão do conhecimento.

\section{Considerações finais}

Ao finalizar essa pequena reflexão sobre o processo de construção do conhecimento emergem algumas considerações. Primeiramente quanto à premente necessidade da precisão dos termos utilizados na vida acadêmica e a oportunidade do aprofundamento do que diz respeito ao processo do conhecimento humano especialmente pelo fato de dar-se ele em áreas distintas como a do imaginário, fundamentada no inconsciente; a motora, resultante de treinamentos; a da apreensão dos valores decorrentes do aprimoramento da sensibilidade e a do desenvolvimento intelectual propriamente dito.
Encontra-se um duplo sentido na expressão "construção do conhecimento" e a amplidão da compreensão dos conceitos de ensino, aprendizagem e pesquisa que vão exigir maior clareza na definição para que se evitem distorções e confusões prejudiciais ao bom andamento do processo educacional.

A noção de "construção do conhecimento" é entendida como constituição de saberes aceitos em determinado tempo histórico e/ou como processo de aprendizagem do sujeito.

Busca-se precisar a conceituação de "construção do conhecimento" segundo Piaget. Prefere-se dá-la a um processo que ocorre de modo espontâneo ou como ato livre e consciente? Em que medida o sujeito se dá conta dessa construção? Em segundo lugar, pergunta-se se essa construção é pessoal e independente ou se segue padrões universais.

Há ainda que refletir sobre os desdobramentos da exigência da ação do sujeito para o construtivismo: sobre o papel do professor e a possibilidade do ensino. Considerando-se suas diferentes interpretações, percebe-se que, para algumas delas, como na de feição sociocultural, a aprendizagem vai depender de agentes externos como o meio social e o professor. $\bigcirc$ ensino ganha relevância como fator essencial na construção do conhecimento, enquanto que, para outras, a aprendizagem depende exclusivamente da atividade do aprendiz.

Ao que parece, a ação do sujeito no plano material pode ser considerada uma excelente prática pedagógica, mas não essencial para a aprendizagem e a 
constituição das estruturas cognitivas que caracterizam as diferentes etapas do seu desenvolvimento.

Percebe-se que o sujeito interfere no processo do conhecimento com a sua atividade como quer Piaget, ou com a sua intencionalidade como pretende Husserl, mas que é sempre preservada a objetividade do conhecimento.

Conclui-se, portanto, que essa "construção" não é totalmente livre e independente o que levaria ao relativismo mas que, deve adequar-se às exigências da intersubjetividade para que seja garantida a possibilidade de comunicação.

Chega-se então à possibilidade de um paralelo entre as noções de atividade do sujeito em Piaget e a de intencionalidade de Husserl que focalizam o sujeito psicologicamente ativo. A exigência para a aprendizagem não estaria numa atividade prática, mas num estado de atividade psíquica que muito se aproxima do interesse ou da intencionalidade husserliana.

Conclui-se ainda que o processo da aprendizagem não se confunde com o da produção científica, mas deve antecedê-lo necessariamente.

aprendizado da ciência leva à compreensão de sua gênese e do processo histórico que a justifica e explicita o seu estatuto de cientificidade.

Tanto o conhecimento do senso comum quanto o científico como modalidades diversas de abordagem do objeto, vão provocar um processo de aprendizagem ou de "construção" no sujeito.
No processo de aprendizagem é necessário, de inicio, a compreensão do conteúdo objetivado podendo essa compreensão, ser entendida como uma construção do conhecimento e, ao mesmo tempo, como uma construção das estruturas cognitivas do sujeito.

Essa "construção" do conhecimento, embora elaborada pelo próprio sujeito, graças à sua intencionalidade que interfere no conteúdo apreendido conferindo-lhe um sentido, não é totalmente independente e autônoma. $\bigcirc$ conhecimento não é apenas relativo ao sujeito, mas objetivo e universal.

Não há, no processo do conhecimento, relativismo, mas, sim, uma relatividade que faz com que ocorra a intersubjetividade entre as diferentes comunidades.

A produção de conhecimento pode então dar-se como conteúdos apreendidos e elaborados pelo sujeito tornando-o mais culto, modificando seu modo de ser, ou como uma inovação na bagagem do saber da humanidade.

Ressalta então a importância do ensino adequadamente feito como desenvolvimento da capacidade de crítica, de análise e de síntese.

Na maior parte das vezes é nesse sentido que se pode dizer que professores e alunos "constróem" o conhecimento. $\bigcirc$ desenvolvimento científico e tecnológico que supõem o conhecimento básico propiciado pelas instituições de ensino é produzido, em geral, pela comunidade científica.

Desse ponto de vista, o ensino torna-se extremamente importante e as pesquisas visando 
ao seu aprimoramento, desejáveis e oportunas.

bom ensino que deve ocorrer não como um armazenamento de informações, mas como formação de referenciais e desenvolvimento da capacidade de avaliação vai ser fundamental para a produção científica e tecnológica.

\section{Referências}

ARCE, A. A formação de professores sob a ótica construtivista. In: DUARTE, N. (Org.). Sobre o construtivismo. Campinas, SP: Autores Associados, 2000.

BACHELARD, S. Logique formelle et logique transcendentale: essai $d$ ' une critique de la raison logique. Paris: Presses Universitaires de France, 1957. Première partie.

BAREMBLITT, G. F. Progressos e retrocessos em psiquiatria e psicanálise. Rio de Janeiro: Global, 1978.

COLL, C. S. Entrevista a Faoze Chibli. Revista Educação, São Paulo, ano 7, n. 78, out. 2003.

HUSSERL, E. Méditations cartésiennes. Tr. de I'allemand par Gabrielle Peiffer et Emmanuel Lévinas. Paris: J. Vrin, 1980.

JAPIASSU, H. Introdução ao pensamento epistemológico. 2. ed. Rio de Janeiro: F. Alves, 1977. . Nascimento e morte das ciências humanas. Rio de Janeiro: F. Alves, 1978.

KANT, E. Crítica da razão pura. Tradução (parcial) de J. Rodrigues Mereja. Rio de Janeiro: Edições de Ouro, 1966.

. La raison pure. Paris: Presses Universitaires de France, 1957.

OLIVEIRA, J. B. A. Construtivismo e alfabetização: um casamento que não deu certo. Ensaio: avaliação e políticas públicas em educação: revista da Fundação Cesgranrio, Rio de Janeiro, v. 10, n. 35, abr./jun. 2002.

PIAGET, J. Epistemologia genética. 2. ed. São Paulo: Martins Fontes, 2002. . Psicologia da inteligência. Rio de Janeiro: Zahar, 1977. . Seis estudos de psicologia. Rio de Janeiro: Forense Universitária, 1978. 
ROSSLER, J. H. Construtivismo e alienação: as origens do poder de atração do ideário construtivista. In: DUARTE, N. (Org.). Sobre o construtivismo. Campinas, SP: Autores Associados, 2000.

SUCUPIRA, N. A condição atual da universidade e a reforma universitária brasileira. Brasília, DF: MEC, 1978.

VIGOTSKY, L. S. Psicologia pedagógica. Porto Alegre: Artmed, 2003.

WERNECK, V. R. Cultura e valor. Rio de Janeiro: Forense Universitária, 2003.

Recebido em: 26/10/2005

Aceito para publicação em: 17/05/2006 